\title{
ADULT ALCOHOL PURCHASE INTENTION: THE INFLUENCE OF HEALTH- CONSCIOUSNESS, ATTITUDES TOWARD ALCOHOL ADVERTISING AND ALCOHOL DRINKERS
}

\author{
Mindaugas Sinkevičius \\ University of Management and Economics, Vilnius, Lithuania
}

\begin{abstract}
ANOTATION
Alcohol consumption and behaviour related to it is a widely discussed topic. The use of alcohol puts risk not just on the individual level, but it compromises the well-being of the society. Although a variety of research focuses exclusively on teenagers, student and adolescent alcohol use issues, the investigation into relation between health-consciousness, attitudes toward alcohol advertising and alcohol drinkers and their effect on adult alcohol purchase intention is scarce. The purpose of the current study is to explore adult alcohol purchase intention phenomenon influenced by individual's health-consciousness, attitude toward advertising, and attitude toward drinkers. The findings reveal that health-consciousness and attitude toward alcohol advertising have a significant negative effect on alcohol purchase intention among adult population, while attitude toward alcohol drinkers indicates significant positive effect. In addition, health-consciousness has a significant negative effect on consumer's attitude toward alcohol drinkers.
\end{abstract}

Keywords: alcohol, health-consciousness, attitudes toward alcohol advertising, attitudes toward drinkers.

\section{INTRODUCTION}

World Health Organization (WHO) reports 2.5 million annual deaths caused by the harmful use of alcohol. The use of alcohol puts risk not just on the individual level, but it compromises the well-being of the society. Although a variety of research focuses exclusively on teenagers, student and adolescence alcohol use issues (Burns et al., 1993; Marcoux, Shope, 1997; Varela, Pritchard, 2011; Sancho et al., 2011; Deshpande, Rundle-Thiele, 2011), only 9\% or 320 thousand of all WHO estimated deaths are in the age group of 15 to 29 years. Certainly, investigation of alcohol related problems among young generation enables to prevent and take actions against the harmful behaviour. However, consumer behaviour is prone to changes over time and therefore different motives might result in different impact. For instance, peer and parental influence as concluded by (Kropp et al., 1999; Park, Lee, 2009; Varela, Pritchard, 2011) or ease of alcohol access (Jang et al., 2013) might have a strong effect on adolescents' inclination to the consumption of alcohol; however these motives have a questionable impact on the adult consumers.

Although, a vast amount of research analysed adolescents' alcohol consumption patterns, the investigation into relation between health-consciousness, attitudes toward alcohol advertising and alcohol drinkers in relation to adult alcohol purchase intention is scarce. A review in alcohol related topics allows concluding that alcohol consumers can usually be categorized into three: those who are frequent or addicted drinkers as "heavy drinkers"; those who consume any alcoholic product occasionally or "moderate drinkers", and those who drink rarely and with little amount of alcohol as "light drinkers" (San Jose et al., 2000). The research attempts to investigate consumer 
purchase intention as a natural consumer behaviour focusing only on the motivation of moderate, occasional or infrequent drinkers.

Consumer behaviour is being influenced by both external and internal stimuli. Disclosure of the determinants enables to predict and influence the possible outcomes of the behaviour. This research is aimed to disclose the effect of suggested phenomenon on adult alcohol purchase intention.

The research paper is structured as follows. First, a brief review presents theoretical insights into the subject. Second, research hypotheses are developed and explored by empirically analysing quantitative data of 388 respondents using structural equation modelling (Lisrel 9.1). Third, discussion and conclusions are presented.

The intended contribution is twofold. First, the research seeks to provide evidence that consumer personal determinants such as health consciousness, attitudes toward alcohol advertising and alcohol drinkers may interact with the consumer's behaviour intentions. Second, whereas vast majority of research concentrated on only adolescents and their stimuli to consume alcohol, the current study employs a broader approach by exploring adult behaviour; thus, the study brings additional light in the field understanding the complexity of consumer behaviour related to alcohol.

\section{LITERATURE REVIEW}

Alcohol and health-consciousness. H. Y. Kim and J.-E. Chung (2011) claim that individuals that are well aware of their health and seek to sustain are considered health-conscious. M. Bui et al. (2011, p. 186) state that "health-consciousness is an indicator of individual overall interest in issues related to general health and health-related consumption." The authors believe that healthconsciousness is stimulated by the intent to protect oneself from harmful products and a wish for social acceptance. Health conscious individuals make healthier consumption choices. N. Michaelidou and L. M. Hassan (2008) believe health-consciousness individuals are well aware of their health status and seek to maintain or improve their health. This particular group of consumers frequently engages in healthy lifestyle and sports activities.

R. Mai and S. Hoffmann (2012) have discovered that health-consciousness determines individual priorities over the choice characteristics. The authors conclude that health-conscious individuals take their health into serious consideration, for instance, searching for information that causes obesity. According to H. Hong (2009), health-conscious consumers are concerned about their health issues and they seek to maintain or improve their health by undertaking particular actions (e.g. engaging in healthy life activities, consuming organic food, and maintaining physical health through sports).

K. S. Fam et al. (2002) refer to alcohol as controversial product, while other studies use terms of "socially sensitive" product. Y. Dong (2010) investigated healthy regular drinkers and found that individuals that were health-conscious consumed less alcoholic beverages. S. J. Gould (1988) hypothesized that health-conscious individuals would have better awareness of health related information and health-consciousness would serve as a preventive mechanism. S. J. Gould's 
research found support for the hypothesis concluding that health-consciousness had an effect on consumers' attitudes towards health related issues.

In this research alcohol is referred to as a health-harmful product and it is presumed that consumers are well aware of the harm alcohol might cause and therefore it is expected that healthconscious consumers are to avoid alcohol as a harmful product. Since alcohol is a harmful product it is predicted that consumer's health-consciousness might negatively affect adult alcohol purchase intention.

Alcohol and attitude toward alcohol advertising. K. K. Bucholz and L. N. Robins (1989) note that advertisements of alcohol are aimed towards men as primary consumer audience. There are several types of advertisements: radio, television, internet, newspaper, flyers, etc. However, the type of existing commercials depends on the country due to different advertisement policies. K. K. Bucholz and L. N. Robins (1989) point out that advertisers claim their advertisements are not intended to increase potential new buyers, they are aimed at alcohol purchasing and drinking audience for the purposes of switching brands. However, that is not necessarily true. In addition to advertising, there are a lot of facts of hidden advertising, for instance in movies.

Similar research concludes misaligned results about the impact of alcohol advertising to the consumer behaviour. In a survey conducted by C. Atkin et al. (1984) of the general American population in the 1980s, when the main medium of advertisements were on print, radio and television, they reported a strong positive correlation between exposure to ads and alcohol drinking. In a study of R. L. Collins et al. (2007), they also observed that 12-year-old children would develop higher probability of drinking when highly exposed to alcohol advertisements. B. Gunter et al. (2010) concluded no significant relationship between advertising and alcohol drinking. K. K. Bucholz and L. N. Robins (1989) claim that alcohol advertising has minor effect on the consumption to individuals exposed to advertising. These authors believe that strict alcohol advertising control policies would not have any substantial effect on the consumer behaviour. On the contrary, other scholars provide evidence that exposure to alcohol advertising may result in higher alcohol consumption patterns. D. P. MacKinnon and H. Lapin (1998) carried out experiments and concluded that constant exposure to alcohol advertising resulted in lower perceived alcohol risks. Advertising campaigns that include famous world known actors, sport athletes, and other celebrities might serve as an important determinant shaping consumer's purchase intentions. Therefore it is predicted that alcohol advertising might be a significant indicator influencing one's purchasing intention. Exposure to advertising was measured using Alcohol advertisement attitude scale.

Alcohol and attitude toward drinkers. Although the majority of studies focus on young generation drinkers, there are some studies examining alcohol consumption patterns of adults. Adult consumers are well aware of the harm alcohol causes and therefore are expected to avoid alcohol. Nevertheless, adults use alcohol. This might be influenced by the outcome expectancies resulted in the use of such product.

Outcome expectancies are judgments about possible outcomes that are probably to occur while engaged in a particular behaviour (Jones et al., 2001). Consumer's expectancies towards a 
certain type of behaviour might be shaped through the personal attitudes towards a drinker. Such attitudes derive from communications among social network members, or by portrayals of behaviours in mass media such as TV or movies that the person watches. These expectancies could be classified into positive and negative. The former are the sets of variables that may reinforce the use of alcohol. Some of these expectancies are socialization, relaxation, altered cognition, assertion, and effective change (Young et al., 2005). For example, positive expectancies like, "I will be more sociable if I have a few drinks" represents an image that is transformed into attitude that alcohol drinkers are more sociable. Therefore such expectancy-induced attitude serves as motivation to drink. The formation of consumer's attitude towards drinker is explained differently across theoretical models. This ranges from concepts of more obvious forms of influence to more indirect forms where social perceptions (e.g. perceiving typical drinker as cool or popular) act as a form of "silent" influence.

Based on scarce previous findings it is predicted that attitude toward drinkers might be a significant indicator affecting consumer's alcohol purchasing intention.

\section{RESEARCH METHODOLOGY}

The data (Table 1) for this research was collected on 2-16 December, 2013 based on a contract with international market researcher, analysis and consulting company TNS. The total of 388 individuals responded in the study. The sample included almost equal number of male and female respondents. Only $4.4 \%$ of the sample respondents were 18-19 years of age, 20-29-year age group accounted for $22.7 \%, 30-39-17.3 \%, 40-49-19.3 \%$, 50 and more $-36.3 \%$ of the sample. According to the monthly income per household member, the respondents fell into four groups. In regard to education, the majority of $89.2 \%$ respondents indicated holding secondary, higher or university degree.

Table 1. Sample profile

\begin{tabular}{|l|c|c||c|c|c|}
\hline \multicolumn{1}{|c|}{ Gender } & Amount & Percent & $\begin{array}{c}\text { Monthly income per household } \\
\text { member in Litas }\end{array}$ & Amount & Percent \\
\hline Male & 192 & 49.5 & Less than 700 & 116 & 29.9 \\
\hline Female & 196 & 50.5 & $701-1400$ & 173 & 44.6 \\
\hline Age & Amount & Percent & $1401-2100$ & 52 & 13.4 \\
\hline $18-19$ & 17 & 4.4 & More than 2101 & 0 & 0 \\
\hline $20-29$ & 88 & 22.7 & Unspecified & 47 & 12.1 \\
\hline $30-39$ & 67 & 17.3 & Education & Amount & Percent \\
\hline $40-49$ & 75 & 19.3 & Primary & 7 & 1.8 \\
\hline 50 and more & 141 & 36.3 & Major & 35 & 9 \\
\hline & & & Secondary & 153 & 39.4 \\
\hline & & & Higher & 110 & 28.4 \\
\hline
\end{tabular}

To operationalize the study constructs three scales were adapted. All of these scales had been validated in previous research. The consumer's alcohol purchase intention was measured using 
3-item scale by R. Spijkerman et al. (2004). Example item: "To what extent do you think you will drink weekly in the future". The respondents were asked to evaluate the given statements of the two phenomena using the 5-point scale, where 1 meant "Not likely" and 5 meant "Very likely."

The consumer's health-consciousness was measured using 4-item scale by S. J. Gould (1988). Example item: "I reflect about my health a lot". The respondents were asked to evaluate the given statements of the two phenomena using the 7-point scale, where 1 meant "Absolutely disagree" and 7 meant "Absolutely agree."

The consumer's attitude toward alcohol advertising was measured using 5-item scale by M. E. Goldberg et al. (2006). Example item: "I get upset when I see some of the ads for beer". The respondents were asked to evaluate the given statements of the two phenomena using the 7-point scale, where 1 meant "Absolutely disagree" and 7 meant "Absolutely agree."

The consumer's attitude toward drinkers was measured using 6-item scale by C. A. Russell et al. (2009). Example item: "I think people who drink are cool". The respondents were asked to evaluate the given statement using the 7-point scale, where 1 meant "Absolutely disagree" and 7 meant "Absolutely agree."

Hypotheses development. The literature review suggests that health-consciousness, attitudes toward alcohol advertising and alcohol drinkers might have significant effect on alcohol purchase intention. Based on that 4 hypotheses were developed:

Hypothesis 1: There is a negative relationship between the consumer's health-consciousness and the alcohol purchase intention.

Hypothesis 2: There is a negative relationship between the consumer's attitude toward alcohol advertising and the alcohol purchase intention.

Hypothesis 3: There is a positive relationship between the consumer's attitude toward drinkers and the alcohol purchase intention.

Hypothesis 4: There is a negative relationship between the consumer's healthconsciousness and consumer's attitude toward drinkers.

The conceptual model (Figure) represents the hypotheses raised.

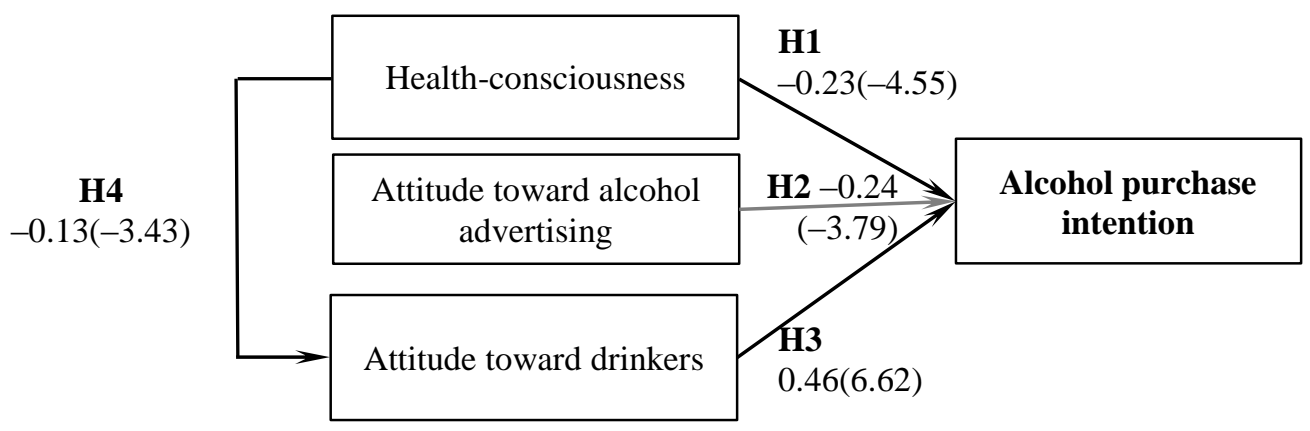

Note. Standardized estimates shown (t-values in brackets).

Figure. Hypothesis testing results 


\section{RESULTS}

To test the hypotheses, we estimated a structural equation model with LISREL 9.1, which produced good fit $\left(\chi^{2}=494.1, d f=224\right.$, RMSEA $=0.050, \mathrm{CFI}=0.977$, SRMR $\left.=0.039\right)$. According to Vieira (2011) RMSEA value $<0.05$ indicates that good model fit. Further, in compliance to R. Bagozzi (1981) recommendations convergent validity was examined by looking at the $t$-values of Lambda-X matrix. All t-values were higher than 2.00 level, ranging from 11.87 to 47.29. As far as the reliability is concerned, all the Cronbach's alphas' (Table 2) range from .0841 to 0.968 and are greater than the 0.7 recommended.

Table 2. Cronbach's alpha estimates

\begin{tabular}{|l|c|c|}
\hline \multicolumn{1}{|c|}{ Scales } & Cronbach's Alpha & N of Items \\
\hline Health-consciousness & 0.846 & 4 \\
\hline Attitude toward alcohol advertising & 0.914 & 5 \\
\hline Attitude toward drinkers & 0.841 & 6 \\
\hline Alcohol purchase intention & 0.968 & 3 \\
\hline
\end{tabular}

Composite reliabilities of measurement models ranged from 0.84 to 0.91 , while average variance extracted (AVE) values ranged from 0.50 to 0.64. All AVEs exceeded the squared correlation between each construct with all other constructs (Fornell, Larker, 1981). The relevant standardized parameter estimates and associated t-values are shown in Figure. Supporting hypothesis 1, 2, 3 and 4: health consciousness is negatively related to alcohol purchase intention $(\beta=-0.23, \mathrm{p}<0.01)$; attitude toward alcohol advertising is negatively related to alcohol purchase intention $(\beta=-0.24, \mathrm{p}<0.01)$; attitude toward drinkers is positively related to alcohol purchase intention $(\beta=0.46, \mathrm{p}<0.01)$; and health consciousness is negatively related attitude toward drinkers $(\beta=-0.13, \mathrm{p}<0.01)$.

\section{DISCUSSION AND CONCLUSIONS}

Alcohol and its consumption has been one of the well documented human social behaviours. Even in the ancient times, alcoholic drinks were recognized to have played a number of roles in religion, traditions and even economics as a trade product. As time progressed, however, the role of alcohol in societies have revealed from mere catalysts of socialization to one of the most saleable product in the market. The unregulated market and consumption of alcohol causes severe personal and societal problems. Frequent alcohol consumption might lead health problems, violence, unplanned sexual activity etc., although efforts have been expended to reduce alcohol use but with little success. Therefore, this research offers some evidence and extends prior research by demonstrating that stimuli those of health consciousness, attitudes toward alcohol advertising and alcohol drinkers interact with the consumers' intentions to purchase alcohol. The research has provided limited insight of alcohol purchase intention. The phenomenon of alcohol purchase intention was analysed from a consumer behaviour perspective, investigating the motives, factors and combinations of those that lead to predicted purchase behaviour that could be encouraged as well as discouraged to consume alcohol. 
Although, adult consumers are rational decision-makers; however they differ in the choice what to buy and what not to buy? Consumer behaviour, purchase intention, in particular, implies keeping to some particular values or norms that serve as guidelines for one's behaviour. Shaw et al. (2005) claim personal characteristics are an important area of academic interest contributing to better understanding of consumer behaviour.

Although many factors may facilitate or impede performance of consumer's behaviour, this research has revealed that adult consumers that are health-conscious tend to demonstrate a lower level alcohol purchase intention. At first sight this finding could be claimed to be obvious, but not necessarily. There are scientific research-based claims that moderate alcohol drinking contributes to a person's total well-being (both physical and mental). For instance, epidemiological studies have shown that individuals who have the habit of daily moderate wine consumption had lower cardiovascular mortality when compared to cases who abstained from it (German, Walzen, 2000). A cup or glass of red wine is suggested to limit the initiation and progression of the atherosclerosis (Szmitko et al., 2005). There are claims that moderate drinking of other alcohols such as beer and spirits are linked with lower risks of developing or suffering from coronary illnesses (Rimm et al., 1996). However this research suggests that health-conscious individuals do not intend to purchase and drink alcohol for the health benefits.

In the research it was discovered that consumer's dissatisfaction with alcohol advertising resulted in lower level alcohol purchase intention. These findings confirm similar conclusions by C. Atkin et al. (1984). Since, consumers are being constantly exposed to alcohol advertising, it affects the intention to purchase alcohol and only individuals dissatisfied with the advertising demonstrate lower purchase intention levels.

In addition it was found that consumers having positive image of alcohol drinkers tend to demonstrate higher levels of alcohol purchase intention. A positive versus negative attitude is an important predictor of purchase intention, meaning that more positive attitude the more likely alcohol is to be purchased. These findings correlate with similar conclusions drawn by N. K. Lee et al. (1999). Finally, it was noted that consumer's health consciousness plays a negative impact towards the image of alcohol drinkers.

Although, alcohol buyers and user are different individuals and the analysed determinants might serve to segment than for better preventative results. Understanding reasons and motivations why people drink would also allow better understanding how people could get addicted to alcohol. Therefore the research findings could be used for the creation of update alcohol consumption reduction policies.

\section{REFERENCES}

1. Atkin, C., Hocking, J., Block, M. (1984). Teenage drinking: Does advertising make a difference? Journal of Communication, 34, 157-167.

2. Bagozzi, R. (1981). Evaluating structural equation models with unobservable variables and measurement error: A comment. Journal of Marketing Research, 18 (8), 375-81. 
3. Bucholz, K. K., Robins, L. N. (1989). Sociological research on alcohol use, problems, and policy. Annual Review Sociology, 15, 163-186.

4. Bui, M., Kemp, E., Howlett, E. (2011). The fight against obesity: Influences of self-efficacy on exercise regularity. Journal of Nonprofit \& Public Sector Marketing, 23, 181-208.

5. Burns, W. J., Hampson, S. E., Severson, H. H., Slovic, P. (1993). Alcohol-related risk taking among teenagers: An investigation of contributing factors and a discussion of how marketing principles can help. Advances in Consumer Research, 20, 183-187.

6. Collins, R. L, Ellickson, P. L., McCaffrey, D. (2007). Early adolescent exposure to alcohol advertising and its relationship to underage drinking. Journal of Adolescent Health, 40, 527-534.

7. Deshpande, S., Rundle-Thiele, S. (2011). Segmenting and targeting American university students to promote responsible alcohol use: A case for applying social marketing principles. Health Marketing Quarterly, 28 (4), 287-302.

8. Dong, Y. (2010). Semiparametric binary random effects models: Estimating two types of drinking behavior. Munich Personal RePEc Archive, 25425, 1-10.

9. Fam, K. S., Waller, D. S., Erdogan, B. Z. (2002). The influence of religion on attitudes towards the advertising of controversial products. European Journal of Marketing, 38 (5/6), 537-555.

10. Fornell, C., Larcker, D. (1981). Evaluating structural equation models with unobservable variables and measurement error. Journal of Marketing Research, 18 (1), 39-50.

11. German, J. B., Walzen, R. L. (2000). The health benefits of wine. Annual Review of Nutrition, 20, 56593.

12. Goldberg, M. E., Niedermeier, K. E., Bechtel, L. J., Gorn, G. J. (2006) Heightening adolescent vigilance toward alcohol advertising to forestall alcohol use. Journal of Public Policy \& Marketing, 25 (2), 147159.

13. Gould, S. J. (1988). Consumer attitudes toward health and health care: A differential perspective. Journal of Consumer Affairs, 22, 96-118.

14. Gunter, B., Hansen, A., Touri, M. (2010). Alcohol Advertising and Young People Drinking: Representation, Reception and Regulation. Basingstoke, UK: Palgrave Macmillan.

15. Hong, H. (2009). Scale Development for Measuring Health Consciousness: Re-conceptualization. 12th Annual International Public Relations Research Conference, Holiday Inn University of Miami Coral Gables, Florida.

16. Jang, S. A., Rimal, R. N., Cho, N. (2013). Normative influences and alcohol consumption: The role of drinking refusal self-efficacy. Health Communication, 28 (5), 443-451.

17. Jones, B. T., Corbin, W., Fromme, K. (2001). A review of expectancy theory and alcohol consumption. Addiction, 96, 57-72.

18. Kim, H., Y., Chung, J.-E. (2011). Consumer purchase intention for organic personal care products. Journal of Consumer Marketing, 28 (1), 40-47.

19. Kropp, F., Lavack, A. M., Holden, S. J. S. (1999). Smokers and beer drinkers: Values and consumer susceptibility to interpersonal influence. Journal of Consumer Marketing, 16 (6), 536-557. 
20. Lee, N. K., Greely, J., Oei, T. P. (1999). The relationship of positive and negative alcohol expectancies to patterns of consumption of alcohol in social drinkers. Addictive Behavior, 24, 359-369.

21. MacKinnon, D. P., Lapin, A. (1998). Effects of alcohol warnings and advertisements: A test of the boomerang hypothesis. Psychology and Marketing, 15 (7), 707-726.

22. Mai, R., Hoffmann, S. (2012). Taste lovers vs. nutrition fact seekers: How health consciousness and selfefficacy determine the way consumers choose food products. Journal of Consumer Behaviour, 11 (4), 316-328.

23. Marcoux, B. C., Shope, J. T. (1997). Application of the Theory of Planned Behaviour to adolescent use and misuse of alcohol. Health Education Research, 12 (3), 323-331.

24. Michaelidou, N., Hassan, L. M. (2008). The role of health consciousness, food safety concern and ethical identity on attitudes and intentions towards organic food. International Journal of Consumer Studies, 32, 163-170.

25. Park, H. S., Lee, D. L. (2009). A test of theory of planned behavior in Korea: Participation in alcoholrelated social gatherings. International Journal of Psychology, 44 (6), 418-433.

26. Rimm, E. B., Klatsky, A., Grobbee, D. Stampfer, M. J. (1996). Review of moderate alcohol consumption and reduced risk of coronary heart disease: is the effect due to beer, wine or spirits? The British Medical Journal, 312, 731. doi: http://dx.doi.org/10.1136/bmj.312.7033.731.

27. Russell, C. A., Russell, D. W., Grube, J. W. (2009). Nature and impact of alcohol messages in a youthoriented television series. Journal of Advertising, 38 (3), 97-112.

28. San Jose, B., van Oers, J. A. M., van de Mheen, H., Garretsen, H. F. L., Mackenbach, J. P. (2000). Drinking patterns and health outcomes: occasional versus regular drinking. Addiction, 95, 865-872.

29. Sancho, F. M., Miguel, M. J., Aldás, J. (2011). Factors influencing youth alcohol consumption intention: An approach from consumer socialization theory. Journal of Social Marketing, 1 (3), 192-210.

30. Shaw, D., Grehan, E., Shiu, E., Hassan, L., Thomson, J. (2005). An exploration of values in socially acceptable consumer decision making. Journal of Consumer Behavior, 4 (3), 185-200.

31. Spijkerman, R., Van den Eijnden, R. J. J. M., Vitale, S., Engels, R. C. M. E. (2004). Explaining adolescents' smoking and drinking behavior: The concept of smoker and drinker prototypes in relation to variables of the theory of planned behavior. Addictive Behaviors, 29, 1615-1622.

32. Szmitko, P. E., Verma, S. (2005). Red wine and your heart. Circulation, 111, e10-11.

33. Varela, A., Pritchard, M. E. (2011). Peer influence: Use of alcohol, tobacco, and prescription medications. Journal of American College Health, 59 (8), 751-756.

34. Young, R. M., Ricciardelli, R., Saunders, J. B. (2005). The role of alcohol expectancy and drinking refusal self-efficacy beliefs in university student drinking. Alcohol and Alcoholism, 41, 70-75. 


\title{
ADULT ALCOHOL PURCHASE INTENTION: THE INFLUENCE OF HEALTH \\ CONSCIOUSNESS, ATTITUDES TOWARD ALCOHOL ADVERTISING AND \\ ALCOHOL DRINKERS
}

\section{Mindaugas Sinkevičius}

University of Management and Economics, Vilnius, Lithuania

\begin{abstract}
Research background. Alcohol consumption and behaviour related to it is a widely discussed topic. World Health Organization (WHO) reports 2.5 million annual deaths caused by the harmful use of alcohol. The use of alcohol puts risk on just on the individual level, but compromises the well-being of the society. Although a variety of researches focuses exclusively on teenagers, student and adolescence alcohol use issues (Deshpande, Rundle-Thiele, 2011; Sancho et al., 2011; Varela, Pritchard, 2011; Marcoux, Shope, 1997; Burns et al., 1993) the investigation in to relation between health consciousness, attitudes toward alcohol advertising and alcohol drinkers and their effect on adult alcohol purchase intention is scarce.

The object of the research is to examining adult alcohol purchase intention phenomenon influenced by individual's health consciousness, attitude toward advertising, and attitude toward drinkers

Methods. The data for this research was collected on December, 2013. A total of 388 filled questionnaires were collected to perform the research. Structural equation modelling (Lisrel 9.1) tools were used to test the proposed hypotheses.

Results. The findings reveal that health consciousness and attitude toward alcohol advertising have a significant negative effect on alcohol purchase intention among adult population, while attitude toward alcohol drinkers indicates significant positive effect.

Conclusions. Adult alcohol purchase intention is a complex phenomenon influenced by both of social and personal determinants. This research paper revealed that consumer's inner characteristics those of health consciousness, attitudes toward alcohol advertising and alcohol drinkers have an effect on adult's alcohol purchase intention. Conclusively, these finding could be ultimately used while seeking the reduction of alcohol amounts consumed.
\end{abstract}

Keywords: alcohol, health-consciousness, attitudes toward alcohol advertising, attitudes toward drinkers. 